\title{
Densidade de plantio e idade de colheita de quebra-pedra [Phyllanthus amarus (Schumach. \& Thonning) genótipo Unicamp-CPQBA 14] na produtividade de filantina
}

\begin{abstract}
MAIA-ALMEIDA, C.I. ${ }^{1-6 *}$; MING, L.C. ${ }^{\text {; }}$ MARQUES, M.O.M. ${ }^{2}$; MAGALHÃES, P.M. ${ }^{3}$; QUEIROZ, S.C.N. ${ }^{4}$; SCRAMIM, S. ${ }^{4}$; MISCHAN, M.M. ${ }^{5}$; MONTANARI-JR, I. ${ }^{3}$; PEREIRA, B. ${ }^{3}$;FERREIRA, M.I. ${ }^{1}$

${ }^{1}$ Setor de Horticultura, Departamento de Produção Vegetal - Faculdade de Ciências Agronômicas - UNESP, Rua José Barbosa de Barros, $n^{\circ}$ 1780, Botucatu-SP, CEP 18. 610-307 Caixa Postal 237; ${ }^{2}$ Laboratório de Produtos Naturais, Fazenda Santa Eliza - Instituto Agronômico de Campinas; ${ }^{3}$ Divisão de Agrotecnologia- Centro Pluridisciplinar de Pesquisas Químicas, Biológicas e Agrícolas - Universidade Estadual de Campinas; ${ }^{4}$ Laboratório de Análise de Resíduos Químicos e de Agrotóxicos da EMBRAPA Meio Ambiente em Jaguariúna-SP; ${ }^{5}$ Departamento de Bioestatística, Instituto de Biociências, Campus de Rubião Jr, UNESP-Botucatu, SP. ${ }^{6} P N P D$-Produção vegetal, Campus Gurupi, Universidade Federal do Tocantins, Rua Badejós, no7, Zona Rural, CEP. 77402-970. Caixa Postal 66*iezidbr@yahoo.com.br
\end{abstract}

\begin{abstract}
RESUMO: Avaliou-se o efeito da densidade de plantio e da idade de Phyllanthus amarus CPQBA14 , sobre o teor e produtividade de filantina. O delineamento experimental foi em blocos ao acaso, em esquema fatorial $4 \times 6$, com cinco repetições, envolvendo 4 tratamentos de densidade de plantio (400.000 $\mathrm{pl} \mathrm{ha}^{-1} ; 200.000 \mathrm{pl} \mathrm{ha}^{-1} ; 100.000 \mathrm{pl} \mathrm{ha}^{-1} \mathrm{e} 66.667,68 \mathrm{pl} \mathrm{ha}^{-1}$ ) com 6 colheitas $(30,45,60,75,90$ e 105 dias após o transplante (DAT)). Os dados foram submetidos a Análise de Variâncias e Regressão $(P>0.001)$. Para o teor de Filantina, foram observados efeitos significativos e independentes dos tratamentos de idade da planta na colheita e densidade de plantio. O teor de filantina aumentou linearmente com a idade da planta, atingindo o máximo aos 105 DAT, com teor de $11,52 \mathrm{~g} \mathrm{Kg}^{-1}$. O adensamento populacional estimado que proporcionou máximo teor de filantina $\left(8,66 \mathrm{~g} \mathrm{~kg}^{-1}\right)$ foi de $299.860 \mathrm{pl} \mathrm{ha}^{-1}$. A produtividade de filantina apresentou interação significativa entre densidade de plantio e idade da planta na colheita. Observou-se que ao longo do crescimento da planta, os tratamentos com 200 e $400.000 \mathrm{pl} \mathrm{ha}^{-1}$ apresentaram as maiores produtividades de filantina $\left(39,3\right.$ e $\left.37,8 \mathrm{~kg} \mathrm{ha}^{-1}\right)$ aos 97,12 e 95,17 DAT, respectivamente. Concluise que o espaçamento apropriado para o melhor arranjo espacial de cultivo é de $299.860 \mathrm{pl} \mathrm{ha}^{-1}$ para as produtividades de $3.974,19 \mathrm{Kg}$ (massa de matéria seca foliar) x 0,00866 kg (teor de filantina) $=34,416 \mathrm{~kg} \mathrm{ha}^{-1}$ de filantina, com colheita programada aos 97 DAT.
\end{abstract}

Palavras-chave: quebra-pedra, cultivo de plantas medicinais, ecofisiologia, qualidade fitoquímica.

\begin{abstract}
Density of planting and age of Phillanthus amarus - genotype UNICAMP/ CPQBA-14 on the productivity of phyllanthin. The effect of planting density and age of Phyllanthus amarus- genotype CPQBA-14, on the content and productivity of phyllanthin were evaluated. The experimental design was randomized blocks in factorial scheme $4 \times 6$, with five replicates, consisting of 4 treatments of planting density $\left(400.000 \mathrm{pl} \mathrm{ha}^{-1} ; 200.000 \mathrm{pl} \mathrm{ha}^{-1}\right.$; $100.000 \mathrm{pl} \mathrm{ha}^{-1}$ and $\left.66667.68 \mathrm{pl} \mathrm{ha}^{-1}\right)$ with six ages of plants (30, 45, 60, 75, 90 and 105 days after transplanting (DAT)). Data were subjected to analysis of variance and regression $(P>0.005)$. For phyllanthin content independent and significant effects of harvest and planting density were observed. The phyllanthin contents increased with plant age, peaking at 105 DAT, with a content of $11.52 \mathrm{~g} \mathrm{~kg}^{-1}$. The estimated population density that provided the high phyllanthin contents (8.66 $\mathrm{g} \mathrm{kg}^{-1}$ ) was at $299.860 \mathrm{pl} \mathrm{ha}^{-1}$. The productivity of phyllanthin showed significant interaction between planting density and plants ages. It was observed during the plant growth, the treatments with 200 and $400.000 \mathrm{pl} \mathrm{ha}^{-1}$ had the highest yield of phyllanthin (39.3 and $37.8 \mathrm{~kg} \mathrm{ha}^{-1}$ ) with 95.17 and 97.12 DAT, respectively. We conclude that the proper spacing for best spatial arrangement of the cultivation is $299.860 \mathrm{pl} \mathrm{ha-1}$ for the yield of $3974.19 \mathrm{~kg}$ (dry weight leaf) $\times 0.00866 \mathrm{~kg}$ (phyllanthin contents) $=34.416 \mathrm{~kg} \mathrm{ha}^{-1}$ of phyllanthin with harvest scheduled at 97 DAT.
\end{abstract}

Key words: Cultivation of medicinal plants, ecophysiology, phytochemical quality, stone breaker

Recebido para publicação: agosto de 2011

Aceito para publicação: dezembro de 2011

Rev. Bras. Pl. Med., Botucatu, v.13, especial, p.633-641, 2011. 


\section{INTRODUÇÃO}

Phyllanthus amarus é popularmente conhecido no Brasil como quebra-pedra sendo utilizado tradicionalmente na medicina popular para problemas de saúde associada ao aparelho urinário. A distribuição dos centros de diversidade desta espécie ocorre em toda região tropical do mundo (Pantropical) sendo o Brasil um dos maiores destes centros (101 sp.) (Silva \& Sales, 2004). Devido ao uso antiviral da espécie na cultura tradicional asiática, cientistas e empresas farmacêuticas investem a mais de uma década em pesquisas com $P$. amarus. Assim, em testes préclínicos, foi confirmado o efeito supressivo na DNA polimerase e na transcriptase viral do HBv (Vírus da hepatite tipo "B") e do HIV (Vírus da síndrome da imunodeficiência adquirida "AIDS") (Notka et al., 2003; Mehrotra et al., 1991). No tocante ao HIV, a ação foi semelhante a do medicamento AZT, podendo ser utilizado na terapia contra esta doença (Notka et al., 2003). Dentre as espécies do gênero, as mais citadas para fins medicinais são Phyllanthus amarus Schumach. \& Thonn. e P. niruri L.. As lignanas filantina e hipofilantina, encontradas nestas espécies são apontadas como responsáveis pelo efeito antiviral contra hepatite B e Aids (Syamsundar et al.,1985). Na Índia, um dos principais países produtores de fitofármacos e fitoterápicos do mundo, $P$. amarus é obtido via extrativismo em ambiente silvestre, áreas urbanas e industriais contaminadas por metais pesados como $\mathrm{Cd}$ sendo comprovado o acúmulo deste metal em suas folhas (Raí et al.,2005). A produção de fitofármacos sob manejo agronômico apresenta-se como melhor alternativa para se obter qualidade, quantidade e segurança para os consumidores. Deve-se ressaltar o risco que o extrativismo oferece para a base genética de espécies e ao ecossistema a que pertence. Atualmente poucos avanços agronômicos para esta espécie foram alcançados e, por conseguinte, não há informações sobre seu comportamento ecofisiológico em um agroecossistema. No Brasil iniciou-se a pesquisa agronômica, por demanda de indústrias farmacêuticas que levaram a avaliação e seleção de genótipos do gênero Phyllanthus L. pelo Centro Pluridisciplinar de Pesquisas Químicas, Biológicas e Agrícolas da Universidade Estadual de Campinas (CPQBAUNICAMP). Sendo que, de forma independente, também pesquisadores da Universidade Federal de Lavras realizaram estudos sobre nutrição mineral. $\mathrm{Na}$ área de plantas medicinais, vários trabalhos relatam a interação entre a idade da planta e os fatores ambientais da fitosfera como determinantes da produção de fitomassa e de metabólitos secundários. O conhecimento do comportamento ecofisiológico das plantas em sistemas de cultivo sob efeito da população ideal de plantas (arranjo espacial) e idade de corte (temporal) tornam-se componentes básicos dos aspectos econômicos e fitotécnicos que subsidiam tomadas de decisão e análise do potencial produtivo e qualitativo da espécie alvo, neste caso, $P$. amarus.

Portanto, o objetivo do presente estudo foi determinar para $P$. amarus Schumach. \& Thonn. (genótipo seleção CPQBA-14) a densidade de plantio e idade de planta para máxima produtividade de biomassa e de filantina bem como aspectos de sua nutrição e crescimento.

\section{MATERIAL E METODO}

A experimentação agrícola e preparo de materiais foi realizada no campo experimental do CPQBA-UNICAMP em Latossolo vermelho (Tabela 01).

TABELA1. Características químicas do solo perfil de $0-20 \mathrm{~cm}$ profundidade da área experimental, denominada Área F no início do experimento. CPQBA/UNICAMP, Paulinia-SP, 2007

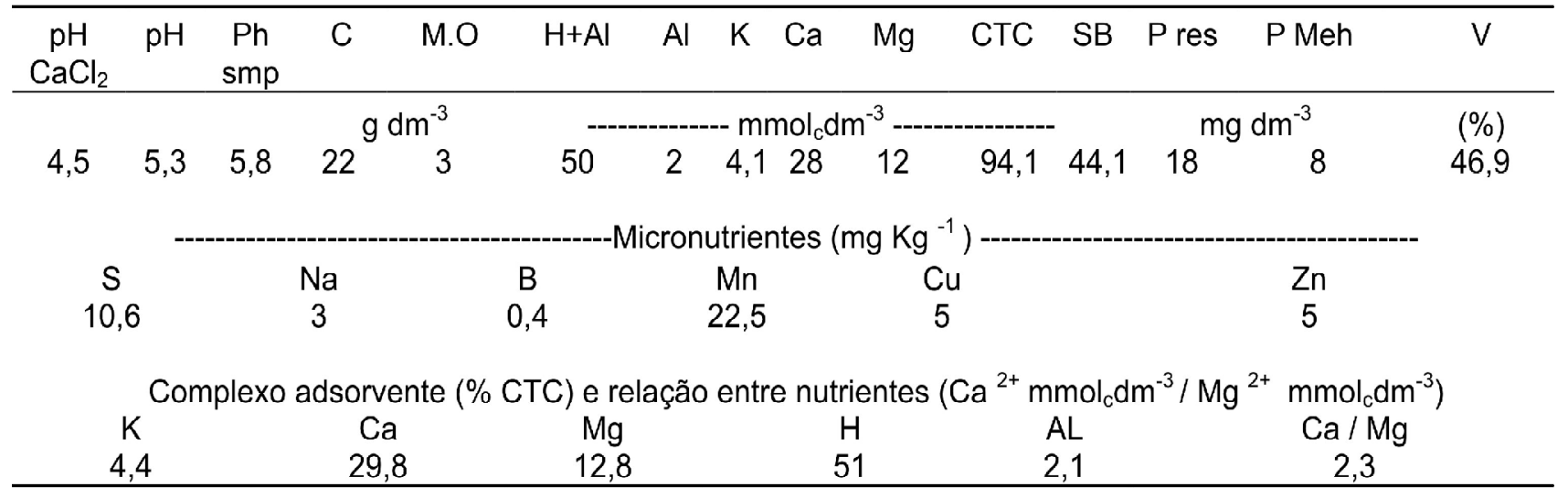

Análises realizadas conforme metodologia aditada pelo laboratório de analises de solo, plantas e fertilizantes UNITHAL realizada em 03/08/2006. RT. Antonio Carlos Marques CREA-SP 129499-7/D.

Rev. Bras. PI. Med., Botucatu, v.13, especial, p.633-641, 2011. 
Para realização dos experimentos elevou-se a $\vee \%$ para 60 . Para determinação das adubações considerou-se os teores de nutrientes $\mathrm{P}, \mathrm{K}, \mathrm{Ca}$ e $\mathrm{Mg}$, $\mathrm{B}, \mathrm{Zn}, \mathrm{Cu}, \mathrm{Mn}$ para nível médio de fertilidade segundo classificação proposta por Raij et al. (2001), em análise conjunta de tomada de decisão associada à resultados experimentais preliminares do CPQBA/ UNICAMP para o gênero e a resultados obtidos em revisão bibliográfica. Realizaram-se adubações básicas na linha de plantio com 30,150, 75 e 3,8 kg ha $^{-1}$ de N, P, K e Zn, respectivamente. A fonte utilizada foi o formulado 4-20-10 + 0,5 de $\mathrm{Zn}$ na dose de 757 $\mathrm{kg} \mathrm{ha}^{-1}$. As mudas foram produzidas a partir de sementes do genótipo CPQBA/UNICAMP-14 em viveiro coberto por sombrite $50 \%$ e sob irrigação diária por meio de sistema automático de aspersão. Para tal, utilizou-se tubetes de plástico com capacidade de $50 \mathrm{~g}$ de substrato cada. O substrato utilizado foi produzido a partir da mistura do substrato comercial G-III® da Gioplantas com $125 \mathrm{~g}$ do adubo N-P-K de liberação lenta PG-MIX ${ }^{\circledR} 14-16-18$ para 25 kg de G$\mathrm{III}^{\circledR}$. O transplantio foi realizado quando as plantas atingiram altura média de $18 \mathrm{~cm}$ aos 45 dias após a semeadura. Os dados climáticos foram coletados e fornecidos pelo CENTRO DE ENSINO E PESQUISA EM AGRICULTURA - CEPAGRI/UNICAMP centro de referência climática para a unidade CPQBAUNICAMP (Tabela 02).

Em cada colheita avaliou-se a o teor, rendimento e produção de extrato metanólico e filantina na parte aérea (folhas) Para análise fitoquímica as amostras foliares foram secas a $40^{\circ} \mathrm{C}$ em estufa com fluxo de ar forçado. Avaliou-se o rendimento de extrato metanólico e de filantina bem como a produtividade de ambos. Para tal procederamse como descrito abaixo:

Para obtenção do extrato metanólico, folhas secas de $P$. amarus foram trituradas em moinho Wiley. Para a preparação do extrato foram utilizadas $1 \mathrm{~g}$ de matéria seca foliar finamente moída e $25 \mathrm{~mL}$ de metanol P.A (Synth). A mistura foi mantida sob agitação contínua em mesa agitadora a 150 rpm por duas horas a temperatura ambiente. Após este período a mistura foi filtrada em papel filtro e o solvente eliminado a pressão reduzida em evaporador rotativo e os extratos acondicionados e frascos de vidro âmbar previamente pesado. Após esta etapa, as amostras foram acondicionadas por 72 horas em dessecador sob vácuo contendo sílica gel. O rendimento do extrato foi obtido por meio da diferença da massa do frasco vazio e o frasco contendo o extrato e cálculo efetuado em relação a massa de matéria seca $(1 \mathrm{~g})$. Para a quantificação da filantina empregou-se cromatógrafo líquido de alta eficiência (Agilent Tecnhologies, 1100 series), constituído de bomba quartenária, injetor automático e detector de absorção no UV/ visível e coluna cromatográfica Inertsil ODS-3 (250nm x 4.6 I.D., GL Sciences Inc. Tokyo, Japan). As condições cromatográficas foram: fase móvel acetonitrila, água (55:45 v/v), eluição isocrática, fluxo de $1 \mathrm{~mL} / \mathrm{min}$ em temperatura ambiente $\left(25^{\circ} \mathrm{C}\right)$ e comprimento de onda de $230 \mathrm{~nm}$ definidos em pré-testes e corroborados por resultados de Murugaiyah \& Chan (2007). O volume de injeção da amostra foi de 20 ìL. O tempo médio de retenção da filantina foi de 12,9 minutos. A curva de calibração de filantina foi feita com padrão comercial (98\%, Cromadex Inc. Miami- Florida- USA) nas concentrações: 50, 25, 15, 10, 5 e $1 \mu \mathrm{g} / \mathrm{mL}$.

O delineamento experimental foi em blocos ao acaso sob esquema fatorial $4 \times 6 \mathrm{com}$ cinco repetições em parcelas subdivididas no tempo para o tratamento idade. Onde os tratamentos principais são: quatro espaçamentos entre plantas $(0,05 ; 0,10$; 0,$20 ; 0,30 \mathrm{~m} \times 0,5 \mathrm{~m}$ entre linhas correspondentes ao espaço planta e densidade de plantio, respectivamente: $0,025 \mathrm{~m}^{2} \mathrm{pl}^{-1} \mathrm{com} 400.000 \mathrm{pl} \mathrm{ha}^{-1}$; $0,05 \mathrm{~m}^{2} \mathrm{pl}^{-1} \mathrm{com} 200.000 \mathrm{pl}^{-1} ; 0,1 \mathrm{~m}^{2} \mathrm{pl}^{-1} \mathrm{com}$ $100,000 \mathrm{pl} \mathrm{ha}^{-1}$ e $0,15 \mathrm{~m}^{2}$ com $\left.66 \cdot 667,68 \mathrm{pl} \mathrm{ha}^{-1}\right)$. Os sub-tratamentos foram seis épocas de colheita após o transplantio em dias (30; 45; 60; 75; 90 e 105 DAT). As parcelas apresentaram dimensões de 6,3 metros de comprimento por 2,5 metros. As subparcelas foram compostas por oito plantas úteis na subparcela para cada época de colheita dentro de cada parcela. Cada sub-parcela (época de colheita) foi intercalada por subbordadura interna bem como por bordadura lateral. $\mathrm{O}$

TABELA2. Dados mensais de precipitação acumulada e amplitudes diárias de temperatura do ar e solo

\begin{tabular}{lcccccc}
\hline Mês & Ano & $\begin{array}{c}\text { oC Max. } \\
\text { AR }\end{array}$ & oC Min. AR & $\begin{array}{c}\text { oC Max. } \\
\text { Solo }\end{array}$ & of Min. Solo & $\begin{array}{c}\text { Precipitação } \\
(\mathrm{mm})\end{array}$ \\
Novembro & 2006 & 28,69 & 17,53 & 31,75 & 22,08 & Mensal \\
Dezembro & 2006 & 29,46 & 19,69 & 32,02 & 23,67 & 248,292 \\
Janeiro & 2007 & 27,57 & 19,35 & 30,35 & 23,16 & 438,404 \\
Fevereiro & 2007 & 30,60 & 19,47 & 34,03 & 23,43 & 201,686 \\
Março & 2007 & 30,69 & 19,27 & 33,46 & 23,55 & 168,920 \\
\hline
\end{tabular}

CENTRO DE ENSINOE PESQUISA EM AGRICULTURA- CEPAGRI/UNICAMP

Rev. Bras. Pl. Med., Botucatu, v.13, especial, p.633-641, 2011. 
número total de plantas por parcela variou com a densidade de plantio (tratamento principal), onde cada parcela do tratamento de $400.000 \mathrm{pl} \mathrm{ha}^{-1}$ comportou 630 plantas, $200,000 \mathrm{pl} \mathrm{ha}^{-1}$ comportou 315 plantas, $100,000 \mathrm{pl} \mathrm{ha}^{-1}$ comportou 158 plantas e por fim a densidade de plantio de $66.667,68 \mathrm{pl}$ ha $^{-1}$ comportou 105 plantas por parcela totalizando 6040 plantas utilizadas no experimento.

Portanto, o arranjo experimental foi fatorial totalizando 24 tratamentos sendo os subtratamentos em parcelas subdivididas no tempo. Realizou-se teste de normalidade de Lilliefors, homogeneidade de variânicas de Chocran \& Bartlet, análises de variância com variáveis complexas, por conseguinte, análises de regressão, modelagem biomatemática. Para os parâmetros que apresentaram respostas de segundo, terceiro e quarto grau realizou-se a estimativa dos pontos de flexão destes e de seu respectivo valor de $v$ com base na precisão e limites do modelo matemático desenvolvido. Para averiguação realizou-se simulações dos mesmos e de cálculo diferencial. Para os parâmetros que apresentaram respostas lineares, adotou-se o critério de $100 \%$ do tratamento quantitativo para máxima resposta (Fernandes et al., 2000). Todas as análises foram realizadas a $5 \%$ de probabilidade. Os softwares utilizados foram: Sistema de Análise Estatística e Genética, "SAEG" V.5.1 UFV-1995; SISVAR- DEX-UFLACNPq- Versão 4.3 (Build 45), Direitos autorais do software reservados à Daniel Furtado Ferreira (1999-2003); Mathematics modeling and simulation system (Maple ${ }^{T M}$ V.11) MAPLESOFT / Waterloo Maple Inc. - 2007 e o pacote estatístico do Exel da Microsoft Inc.

\section{RESULTADO E DISCUSSÃO}

Para o teor de Filantina, foram observados efeitos significativos e independentes dos tratamentos época de colheita (Figura 01) e densidade de plantio (Figura 02).

O teor de filantina aumentou linearmente com a idade da planta dentro da época de colheita, atingindo máximo aos 105 DAT com teor de $11,52 \mathrm{~g} /$ $\mathrm{Kg}$ de massa de matéria seca foliar em função do tempo, ou seja, 1,152\% m/m (Figura 01).

Tal fato possivelmente seja função da quantidade de tecidos fisiológicamente adultos com maior potencial de produção desta molécula. De acordo com Barbosa Filho (2001), o teor de lignanas é função direta da idade da planta, sendo menos susceptível a fatores ambientais. Em complemento, resultados observados por Salomé (2007) e Teratomo et al. (2008) mostram ser variável tal afirmação. Para tanto, esses autores observaram que o estresse hídrico elevou em mais de $100 \%$ o teor de filantina no Genótipo CPQBA-14 de P. amarus devido participação deste metabólito no mecanismo de proteção contra a peroxidação lipídica das células do tecido foliar. Assim, com base no supracitado estudo, pode-se adicionar na generalidade, uma exceção para $P$. amarus, que mostram a importância da variável ambiental sobre a biossíntese lignana filantina. O Teor filantina sob efeito da densidade de plantio, o $P$. amarus -CPQBA-14 respondeu isoladamente e significativamente com regressão quadrática com o aumento da densidade de plantio (Figura 02).

O adensamento populacional crítico para máximo teor de filantina estimado foi de $299.860 \mathrm{pl}$ ha ${ }^{-1}$ com teor/concentração $(\mathrm{m} / \mathrm{m})$ de $8.66 \mathrm{~g} \mathrm{~kg}^{-1}$ de filantina na massa de matéria seca das folhas. A produtividade de Filantina apresentou interação

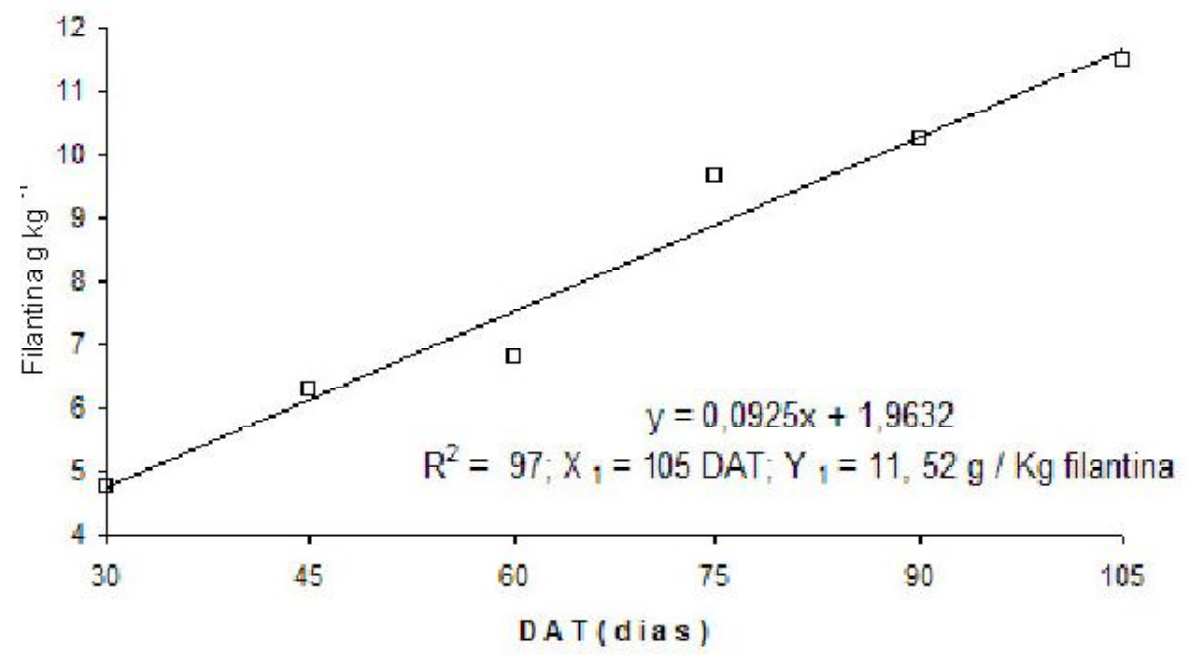

FIGURA1. Teor de médio de filantina na massa de matéria seca foliar em função da época de colheita de plantas de $P$. amarus -CPQBA-14, ou seja, independente da densidade de plantio. 


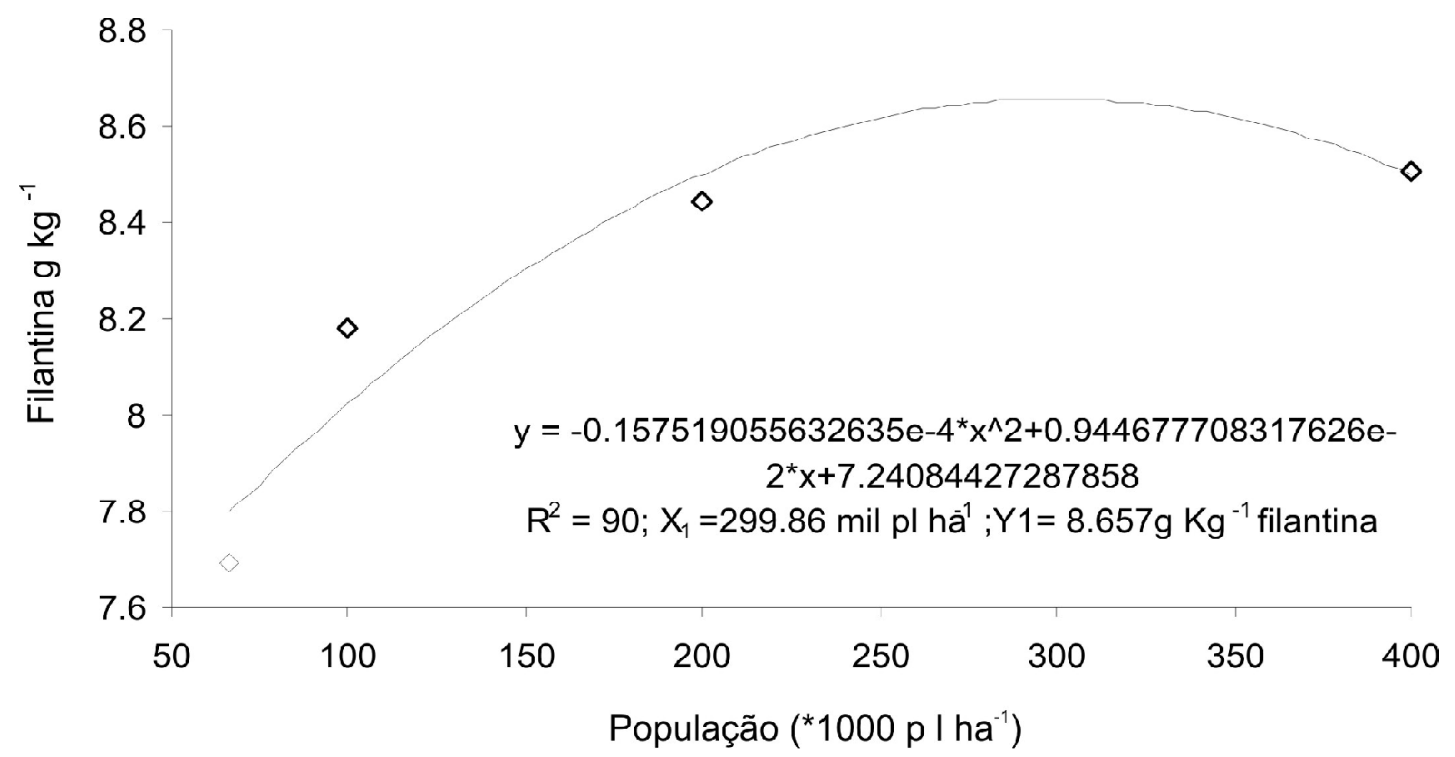

FIGURA 02. Teor médio de filantina na massa de matéria seca foliar em função da densidade de plantio/ população ( ${ }^{*} 1000 \mathrm{pl} \mathrm{ha}^{-1}$ ) de P. amarus -CPQBA-14, ou seja, independente da época de colheita.

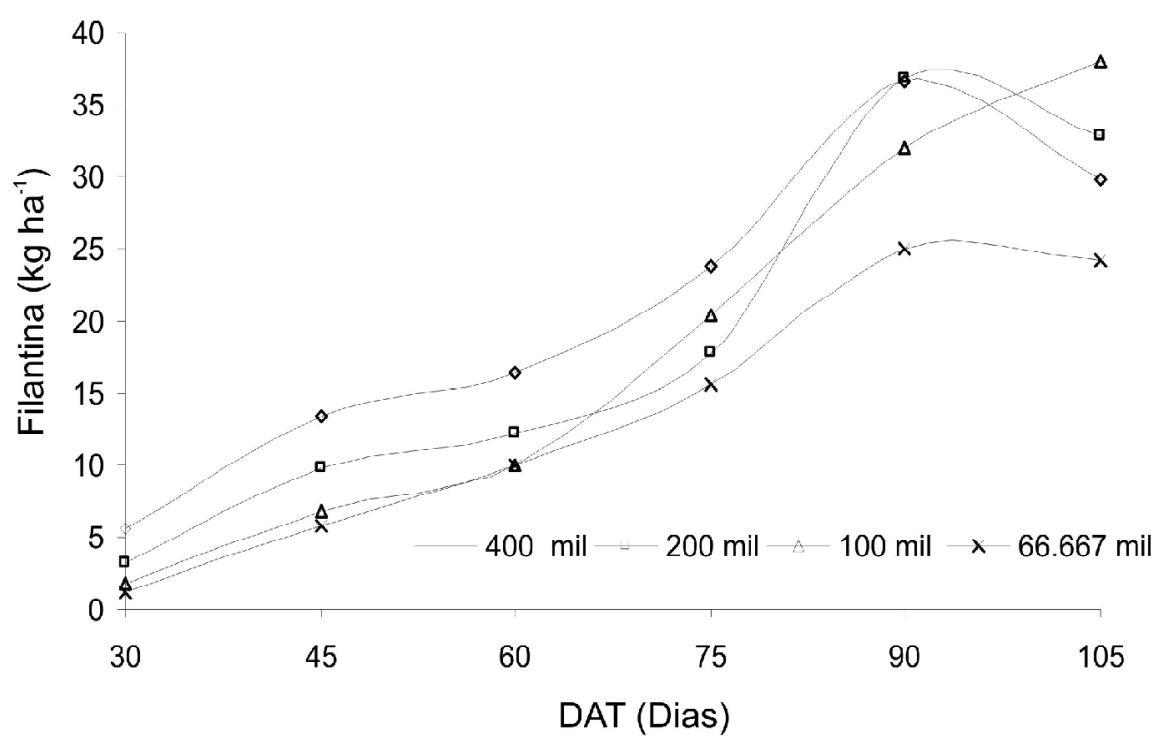

FIGURA 03. Produtividade filantina nas folhas de plantas de $P$. amarus -CPQBA-14 para cada densidade de plantio $\left(\mathrm{p} \mathrm{I} \mathrm{h}^{-1}\right)$ em função de DAT.

significativa entre densidade de plantio e época de colheita (Figura 03, Tabela 03). Observou-se que ao longo crescimento da planta, os tratamentos com 200 e $400.000 \mathrm{pl} \mathrm{ha}^{-1}$ apresentaram as maiores produtividades aos 97,12 e 95,17 DAT com 39,3 e $37,8 \mathrm{~kg} \mathrm{ha}^{-1}$ de filantina, respectivamente (Figura 03; Tabela 03).

Demais tratamentos foram inferiores a estes (Tabela 03).

Resultados tão diversos, quando se atinge níveis críticos de competitividade, pode-se explicar em função do possível aumento na atividade de agentes oxidativos causadores de destruição da parede celular em condições limitantes do ambiente, seja por excesso ou deficiência de luz, $\mathrm{CO} 2$, nutrientes e água, dentre outros (Taiz \& Zeiger, 2004; Larcher, 2000; Mohr \& Schopfer, 1995). Teratomo et al. (2008) identificaram a interação da síntese desta lignana em plantas sob condições de estresse oxidativo relacionados a peroxidação lipídica principalmente em função da ação de peróxidos e superóxidos dentre outros de origem intrínseca a fisiologia da planta. Diante disto, variações na biossíntese e acúmulo de Filantina pode ser variável, seja causado por déficit hídrico ou elicitação por radicais metálicos - $\mathrm{Cu}^{2+}$ e Cd (Santiago et al., 2000; Raí et al., 2005). Portanto, é importante partir da biossíntese de lignanas que se relacionam a teoria 
TABELA 03. Modelos matemáticos para produtividade de filantina em folhas em $P$. amarus -CPQBA-14 em função da época de colheita e densidade de plantio ( $\mathrm{pl} \mathrm{ha}^{-1}$ ). CPQBA-UNICAMP, Paulinia, 2006-2008

\begin{tabular}{|c|c|c|c|c|c|c|c|c|}
\hline \multicolumn{3}{|c|}{ Modelos matemáticos } & $\mathrm{X}_{1}$ & $X_{2}$ & $x_{3}$ & $\hat{Y}_{1}$ & $\hat{\gamma}_{2}$ & $\hat{\mathrm{Y}}_{3}$ \\
\hline${ }^{*}$ Trat & Filantina & $\mathrm{R}^{2}$ & & DA & .... & -..---k & ha $^{-1}$..... & \\
\hline $\begin{array}{l}66.66 \\
7\end{array}$ & $\begin{array}{l}Y=0.339945523809524^{\star} X- \\
9.31475619047619\end{array}$ & 95 & - & - & 105 & - & - & 27,4 \\
\hline 100 & $\begin{array}{l}Y=.507028571428572^{*} X- \\
16.0594285714286 \\
Y=-0.181028806584358 \mathrm{e}-\end{array}$ & 96 & - & - & 105 & - & - & 31,67 \\
\hline 200 & $\begin{array}{l}4^{*} x^{\wedge} 4+0.470964334705063 e-2^{*} x^{\wedge} 3- \\
.4301324074074^{*} x^{\wedge} 2+16.613794532627 \\
{ }^{*} x-220.847380952372\end{array}$ & 99 & 42,8 & 55,22 & 97,12 & 10,79 & 9,67 & 39,3 \\
\hline 400 & $\begin{array}{l}Y=-0.142633744855964 e- \\
4^{\star} x^{\wedge} 4+0.365484224965697 e-2^{\star} x^{\wedge} 3- \\
.33107962962962^{*} x^{\wedge} 2+12.88732716049 \\
34^{\star} x-170.313333333327\end{array}$ & 99 & 48,5 & - & 95,17 & 13,98 & - & 37,8 \\
\hline
\end{tabular}

${ }^{*}$ Trat $=x 1000 \mathrm{pl} \mathrm{ha}{ }^{-1}$; Equações significativas a $\mathrm{P}<0,05$ pelo teste $\mathrm{F}$. - Pontos detectados fora da margem de segurança das equações na simulação e modelagem matemática.

quimiossistemática e adaptativa de espécies conforme Gottlieb \& Yoshida (1984), considerando demais hipóteses e resultados relatados no artigo em questão. Rai et al. (2005) detectou que o estresse oxidativo causado pelo Cd também elevou os teores da Filantina. Corroborando com este autor, Santiago et al. (2000) detectou de forma contundente a relação direta entre a aplicação de agente elicitor metálico $\mathrm{Cu}^{+}$com a atividade da PAL e com o acúmulo de compostos fenólicos no mesófilo de $P$. teneleus.

Para o extrato seco metanólico não foi observada a interação entre os tratamentos. Assim, em função da época de colheita (DAT), o efeito significativo com regressão linear do rendimento de extrato na época de colheita (\%) com máxima produção aos 105 DAT de $29.81 \%$ (Figura 04).

O rendimento de extrato não apresentou efeito significativo da densidade de plantio onde o valor médio deste parâmetro para este tratamento foi de $24.29 \% \mathrm{~m} / \mathrm{m}$ (Figura 05).

Murugaiyah \& Chan (2007) detectaram em $P$. niruri por meio de Soxhlet rendimento de $20.5 \%$

FIGURA 4. Rendimento $(\mathrm{m} / \mathrm{m})$ médio de extrato $(\%)$ metanólico seco da massa de matéria seca foliar ( $\mathrm{mmsf}$ ) em função da época de colheita de $P$. amarus -CPQBA-14,

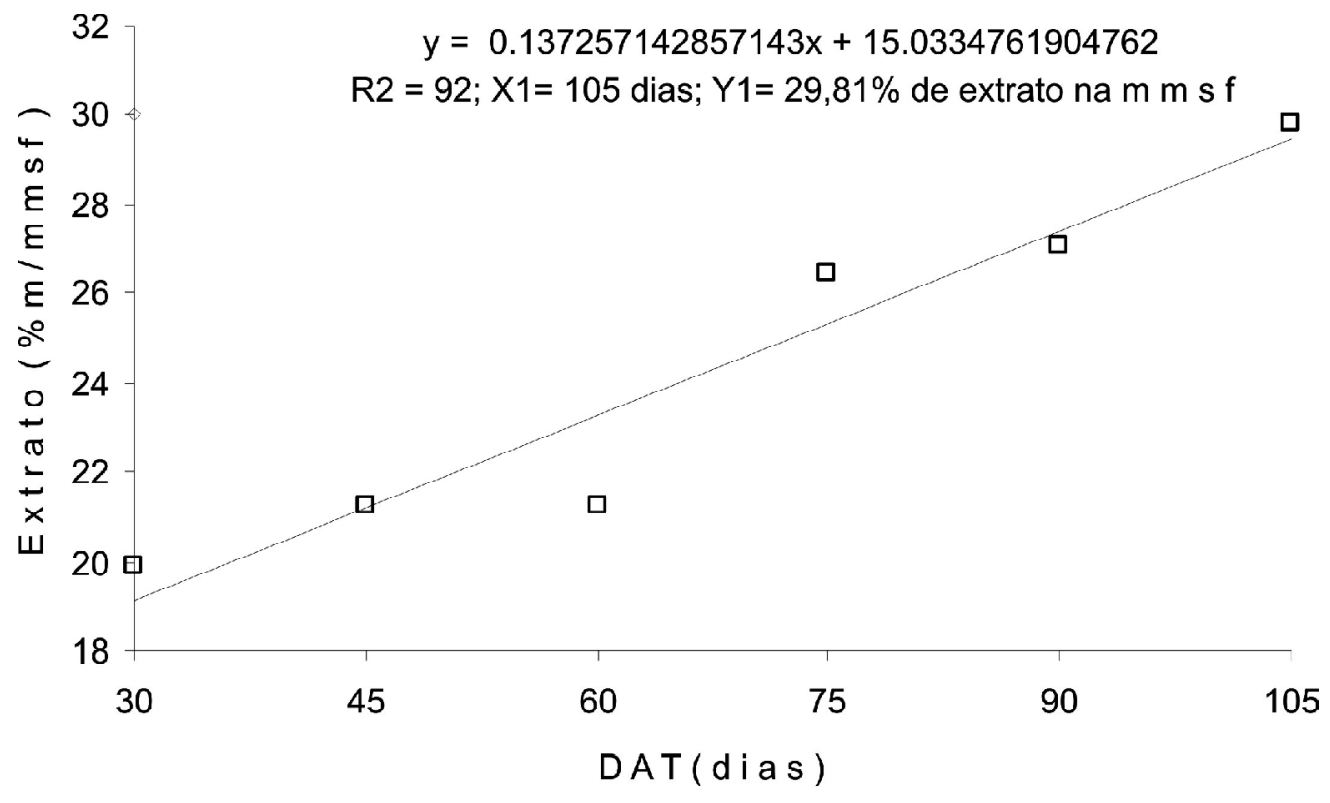

Rev. Bras. Pl. Med., Botucatu, v.13, especial, p.633-641, 2011. 


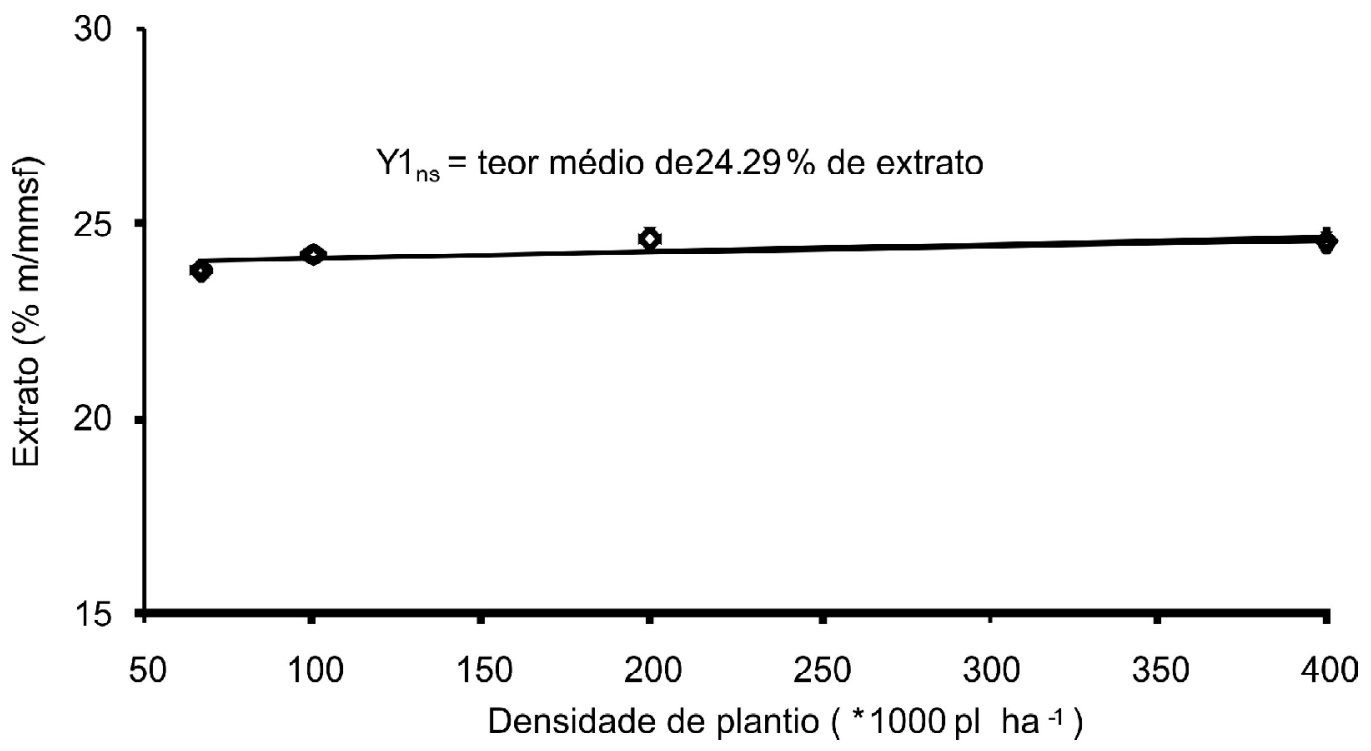

FIGURA 5. Rendimento $(\mathrm{m} / \mathrm{m})$ médio de extrato $(\%)$ metanólico seco da massa de matéria seca foliar (mmsf) densidade de plantio ( $\left.{ }^{*} 1000 \mathrm{pl} \mathrm{ha}^{-1}\right)$ de $P$. amarus -CPQBA-14,

de extrato seco de folhas. Tal fato mostra que ainda há necessidade de estudos sobre métodos de produção de extrato. Farooqi \& Sreeramu (2004) detectaram para $P$. amarus teor médio de 0,4 a 0,5 $\%$ de filantina aos 90 dias após transplantio. Assim, diante dos relatos destes autores e dos resultados do presente trabalho, considerando as possibilidades de variações experimentais entre Índia e Brasil há superioridade do genótipo 14 CPQBA-UNICAMP tanto para produtividade em um único corte quanto para qualidade fitoquímica em termos de filantina quando comparado ao acesso Indiano Navyakrit produzido pelo CMAP em Lucknou - Índia.

Quanto a produtividade, o extrato Metanólico das folhas de $P$. amarus apresentou mesma resposta da filantina, ou seja, efeito significativo da interação entre os tratamentos.

De forma geral, a maior produtividade média foi aos 97,7 DAT com $915.75 \mathrm{Kg} \mathrm{ha}^{-1}$ de massa de extrato metanólico seco (Figura 06 e Tabela 04).

Para tal considerou-se a média de (28.239 \%) rendimento de extrato, em relação a massa de matéria seca foliar média $\left(3242,845 \mathrm{~kg} \mathrm{ha}^{-1}\right)$, logo uma produtividade média $915,747 \mathrm{~kg} \mathrm{ha}^{-1}$ de extrato Metanólico seco, independente da densidade de plantio.

Para melhor entendimento dos resultados acima, ressalta-se que autores relatam que a atividade

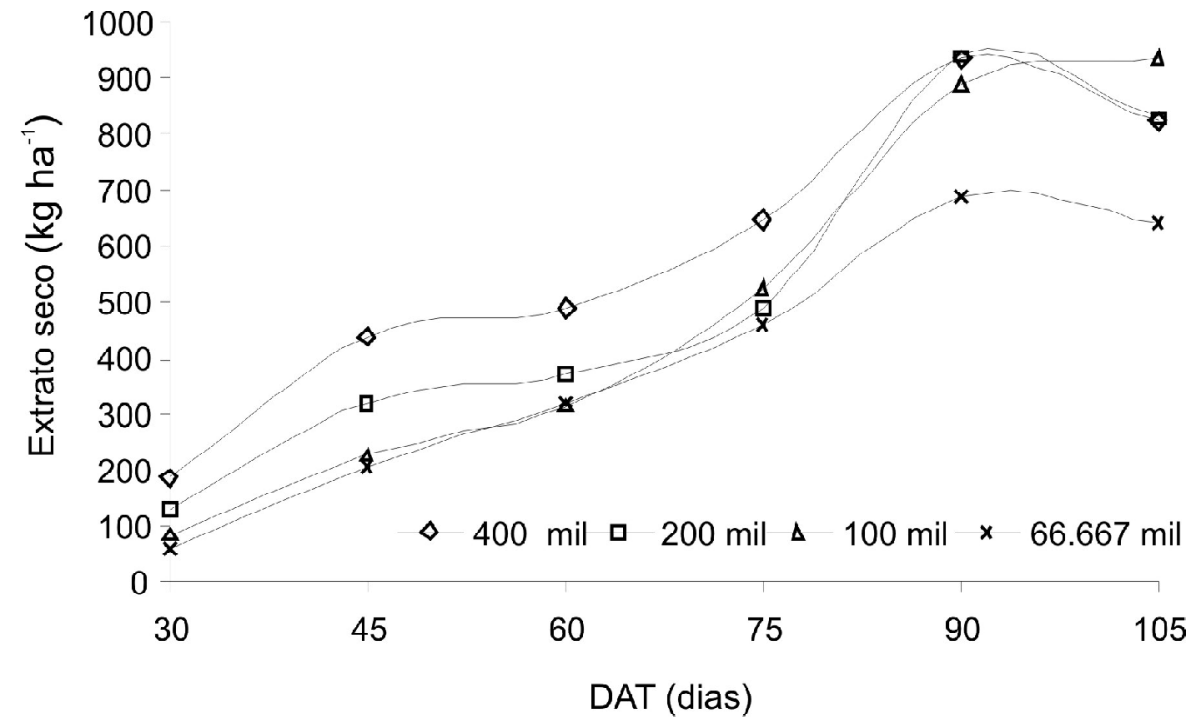

FIGURA 06. Produtividade de extrato metanólico seco das folhas de plantas de $P$. amarus -CPQBA-14 para cada densidade de plantio $\left(\mathrm{p} \mathrm{I} \mathrm{h} \mathrm{a}^{-1}\right)$ em função de DAT. 
da enzima PAL e os produtos biossintetizados por seu intermédio podem ser direcionados pela sensibilidade desta enzima a fatores ambientais (Buchanan et al., 200; Larcher, 2000).

Contudo, a melhor produtividade de extrato metanólico foi detectada aos 95 DAT com produtividade de $990,5 \mathrm{~kg} \mathrm{ha}^{-1}$ e com espaçamento de $10 \mathrm{~cm}$ entre plantas, ou seja $200.000 \mathrm{pl} \mathrm{ha}^{-1}$ (Figura 06 e Tabela 04).

Com base nos resultados obtidos 0 tratamento de densidade de plantio não afetou de forma negativa a fisiologia da planta, lembrando que Salomé (2007) e Teratomo et al. (2008) relatam ser a biossíntese de filantina e outros fenóis estão relacionada ao estresse oxidativo, aumentando seu teor em função do aumento da peroxidação lipídica, por exemplo.

Porém, a produtividadae de filantina foi afetada devido a aumento da massa de folhas fisiológicamente maduras, corroborando Barbosa Filho (1999). Portanto, no presente estudo não se observou efeito das densidades de plantio nos teores de filantina, indicando que tal variação no meio não propiciou estresses causadores de peroxidação lipídica. Conforme correlação observada por Salomé (2007) na produção de flavonóides, por exemplo, de produto via do ácido chiquímico, torna-se determinante o estádio fenológico, drenos e fontes adequados, fotossíntese plena, nutrientes, luz, CO2, energia e aminoácido fenilalanina disponível (Mann, 1994; Taiz \& Zeiger, 2004; Marschner 1995; Herbert, 1989).

De forma geral, a biossíntese de metabólitos secundários apresenta custo energético e de carbono que pode competir ou ser favorecido pelo metabolismo primário, dependendo do seu status e das relações ambientais (Gobbo-Neto \& Lopes, 2007; Gotlieb et al., 1996; Marchese, 1999; Marchese \& Figueira, 2005).

Gotlieb et al. (1996) destaca que, como exemplo, de vulnerabilidade ambiental a síntese e acúmulo de compostos de rota metabólica mista, como os flavonóides e fenilpropanóides, podem variar em instantes sua concentração em função dos fatores ambientais. Assim, estudos mais detalhados sobre as relações ecofisiológicas de ambientes de cultivo e produção de lignanas e neolignanas devem ser estudados.

Analisando os resultados obtidos de pela ótica da viabilidade econômica, a produtividade obtida apesar de significativamente diferente entre 0 tratamento com $0.05 \mathrm{~m}$ entre plantas em relação ao de $0.10 \mathrm{~m}$, representa o dobro de plantas por hectare. Diante disto, a diferença detectada entre os dois tratamentos com resultados proeminentes, acima referidos, traz uma questão primordial para análise da viabilidade agronômica: Realização de estudos sobre o custo de implantação; Análise do custeio da cultura; Análise da viabilidade logística; Estudo de interferência e viabilidade econômica sobre o processamento industrial, para obtenção da filantina, do extrato seco ou planta seca estabilizada.

Com o intuito de se definir resultados práticos, neste experimento, o fator produtividade deve ser considerado e analisado conforme segue abaixo: $O$

TABELA4. Modelos matemáticos da produtividade do extrato seco metanólico $(\mathrm{Me} O \mathrm{OH})$ das folhas de $P$. amarus -CPQBA-14 em função da época de colheita e densidade de plantio $\left(\mathrm{p} \mathrm{I} \mathrm{h}^{-1}\right)$. CPQBA-UNICAMP, Paulinia, nov 2006 a março de 2007.

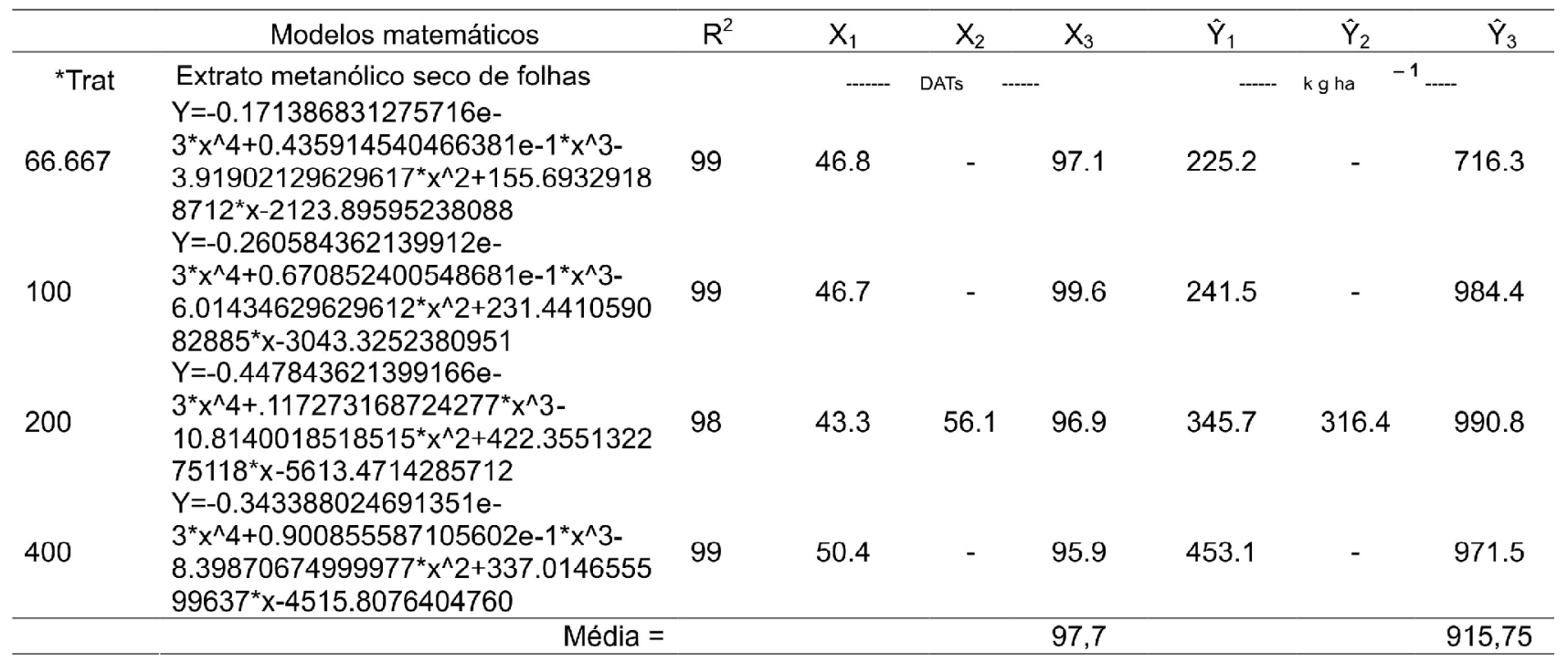

* Trat $=\times 1000 \mathrm{pl} \mathrm{ha}^{-1}$; Equações significativas a $\mathrm{P}<0,05$ pelo teste $\mathrm{F}$. - Pontos detectados fora da margem de segurança das equações na simulação e modelagem matemática

Rev. Bras. PI. Med., Botucatu, v.13, especial, p.633-641, 2011. 
maior teor de Filantina, independente da idade de colheita, atingiu seu ponto máximo na densidade de plantio estimada de $Y=299,860 \mathrm{pl} \mathrm{ha}^{-1}$ teor de 8.66 $\mathrm{g} \mathrm{kg}^{-1}$ de massa de matéria seca foliar (Figura 02); As densidades de 200.000 e $400.000 \mathrm{pl} \mathrm{ha}^{-1}(0,1 \mathrm{e}$ $0.025 \mathrm{~m}^{2} \mathrm{pl}^{-1}$ espaço planta, respectivamente) atingiram maiores produtividades estimadas de 97,12 e 95,17 DAT com 39,3 e 37,8 $\mathrm{kg}^{\text {ha }}{ }^{-1}$ de filantina, respectivamente (Figura 03; Tabela 03). O maior teor de filantina em função da época de colheita e independente da densidade de plantio foi atingida aos 105 dias, devido a comportamento linear estatístico da equação de regressão com 1,152 \% (Figura 01); O respectivo espaço planta para as densidades observadas são: 0.05 e $0.025 \mathrm{~m}^{2} \mathrm{pl}^{-1}$ ao passo que, para densidade estimada do item 1 obteve-se 299.860 $\pm 3 \mathrm{pl} \mathrm{ha}^{-1}$ é de $0,0333485 \mathrm{~m}^{2} \mathrm{pl}^{-1}$ correspondente a $0.066697 \mathrm{~m}$ entre planta com espaçamento entre linha de $0,50 \mathrm{~m}$; A média dos tratamentos 200 e 400.000 pl ha, de maior produtividade de massa de matéria seca foliar entre as densidades é de $13.2535 \mathrm{~g} \mathrm{pl}^{-1}$; Considerando espaçamento de plantio estimado no arranjo $0.066697 \times 0.5 \mathrm{~m}$, uma população estimada de $299.860 \mathrm{pl} \mathrm{ha}^{-1}$ multiplicada pela produção média dos melhores tratamentos de produtividade de filantina e de massa de matéria seca entre os 90 e 105 H" 97,5 DAT com colheita na última data, estima-se potencial produtivo de $3974,19 \mathrm{~kg} \mathrm{ha}^{-1}$ de massa de matéria seca foliar;

Portanto, conclui-se que o espaçamento apropriado para o melhor arranjo espacial de cultivo é de $6.66976 \mathrm{~cm}$ entre plantas por $50 \mathrm{~cm}$ entre linhas, totalizando $299.860 \mathrm{pl} \mathrm{ha}^{-1}$ com respectivo espaço/ planta de $0,0333488 \mathrm{~m}^{2} \mathrm{pl}^{-1}$ para as produtividades de $3974,19 \mathrm{Kg}$ (massa de matéria seca foliar) * $0.00866 \mathrm{~kg}$ (teor de filantina) $=34.416 \mathrm{~kg} \mathrm{ha}^{-1} \mathrm{de}$ Filantina e aproximadamente $965.331 \mathrm{~kg}$ de extrato metanólico com colheita programada aos 97 DAT.

\section{AGRADECIMENTO}

Ao CNPQ pelo apoio financeiro

\section{REFERÊNCIA}

BARBOSA FILHO, J.M. Lignanas, neolignanas e seus análogos. In: SIMÕES, C.M.O; SCHENKEL, E.P., GOSMANN, G., MELLO, J.C.P.; MENTZ, L.A.; PETROVICK, P.R. Farmacognosia: da planta ao medicamento. Porto Alegre: Ed. UFRGS / UFSC, $3^{\circ}$ ed., , p. 481-498. 2000 FERNANDES, L.A.; FURTINI NETO, A.D.; FONSECA, F. C.; RIBEIRO DO VALE, F. Crescimento inicial, níveis críticos de fósforo e frações fosfatadas em espécies florestais. Pesquisa Agropecuária Brasileira, Brasília, v.35, n.6, p. 1191 - 1198, 2000.

HERBERT, R.B. The biosynthesis of secondary metabolites. 2 ${ }^{\mathrm{a}}$ Ed. 231 p. 1989.
GOBBO-NETO, L. \& LOPES, N.P. Plantas medicinais: fatores de influência no conteúdo de metabólitos secundários. Química Nova, v.30, n.2, p.374-381, 2007. GOTLIEB, O.; KAPLAN, M.A.C.; BORIN, M.R. de M.B. Biodiversidade: um enfoque químico-biológico. Rio de Janeiro: Editora UFRJ, 1996, 268p.

MANN, J. Chemical aspects of biosynthesis. New York: Oxford Science publications, 1994, 44 p.

MARSCHNER, H. Mineral nutrition of higher plants. London: Academic Press, 1995, 850p.

MARCHESE, J.A. Produção e detecção de artemisinina em plantas de Artemisia annua L. submetidas a estresses abióticos. 1999, 97 p. (Dissertação de mestrado em Ciências Biológicas). Instituto de Biologia, UNICAMP, Campinas-SP.

MARCHESE, J.A.;FIGUEIRA, GM. O uso de tecnologias prée pós-colheita e boas práticas agrícolas na produção de plantas medicinais e aromáticas. Revista Brasileira de Plantas Medicinais, Botucatu-SP, v.7, n. 3, p.86-96, 2005.

MEHROTRA, R.; RAWAT, S.; KULSHRESHTHA, D.K.; GOYAL, P.; PATNAIK, G.K.; DHAWAN, B.N. In vitro effect of Phyllanthus amarus on hepattis B virus. Indian Journal of Medicinal Researches. v.93, p.71-73, 1991.

MURUGAIYAH, V.; CHAN, K.T. Determination of four lignans in Phyllanthus niruri L. by a simple highperformance liquid chromatography method with fluorescence detection. Journal of Chromatography Archives, v.11, n.54, p.198-204, 2007.

NOTKA, F.; MEIER, G.R.; WAGNER, R. Inhibtion of wildtype human immunodeficiency virus and reverse transcriptas or-resistant variants by Phyllanthus amarus. Antiviral research, v.53, p.175-186, 2003.

RAÍ, V.; KHATOON, S.; BISHT, S.S.; MENHOTRA, S. Effect of cadmium on growth, ultramorphology of leaf and secondary metabolites of Phyllanthus amarus Shum. \& Thonn. Chemosphere, v. 61, p. 1644-1650, 2005.

RAIJ, B. VAN; ANDRADE, J.C.; CANTARELLA, H.; QUAGGIO, J.A. (Ed.). Análise química para avaliação da fertilidade de solos tropicais. Campinas: Instituto Agronômico, 2001. 285p.

SALOMÉ, J.R. Análise fitoquimica dos principios ativos, filantina, hipofilantina e nirantina da quebra-pedra (Phyllanthus amarus Shumach \& Thonn) sob condições de deficit hídrico. 2007, 93p. Dissertação (Mestrado em Fisiologia e Bioquímica de Plantas) Escola Superior de Agricultura "Luiz de Queiroz". Universidade de São Paulo, Piracicaba, SP.

SILVA, M.J.; SALES M.F. O gênero Phyllanthus L. (Phyllantheae - Euphorbiaceae Juss.) no bioma Caatinga do estado de Pernambuco - Brasil. Rodriguésia. v.55, n.84, p.101-126, 2004.

SYAMSUNDAR, K.V.; SINGH, B.; THAKUR, R.S.; HUSSAIN, A.; KISO, A.; HIKINO, H. Antiepatotoxic principles of Phyllanthus niruri Herb. Journal of Ethnopharmacology, v. 14, p.41-44, 1985

TAIZ, L.; ZEIGER, E. Fisiologia Vegetal. SANTARÉM, E.R. (Tradução), 3.ed. Porto Alegre: Artmed, 2004. 719p.

TERATOMO, J.R.S.; OLIVEIRA, R.F.; SANTOS, S.; REHDER, V.L.G. Avaliação dos teores das lignanas filantina, hipofilantina e niratina em quebra-pedra (Phyllanthus amarus Schumach. \& Thonn.) sob diferentes condições de deficiência hídrica. Revista Brasileira de Plantas Medicinais, v.10, n.4, p.67-75, 2008. 